\title{
Dietary fat: assessing the evidence in support of a moderate-fat diet; the benchmark based on lipoprotein metabolism
}

\author{
P. M. Kris-Etherton ${ }^{1 *}$, A. E. Binkoski ${ }^{1}$, G. Zhao ${ }^{1}$, S. M. Coval ${ }^{1}$, K. F. Clemmer ${ }^{1}$, K. D. Hecker ${ }^{1}$, \\ H. Jacques ${ }^{2}$ and T. D. Etherton ${ }^{3}$ \\ ${ }^{l}$ Nutrition Department, The Pennsylvania State University, University Park, PA, USA \\ ${ }^{2}$ Departement des Sciences des Aliments et de Nutrition, Universite Laval, Sainte-Foy, Quebec, Canada \\ ${ }^{3}$ Department of Dairy and Animal Science, The Pennsylvania State University, University Park, PA, USA
}

\begin{abstract}
There is a growing database that has evaluated the effects of varying amounts of total fat on risk factors for cardiovascular disease, diabetes and overweight and obesity. The evidence clearly suggests that extremes in dietary fat should be avoided, and instead a diet moderate in total fat (25-35\% energy) is preferable for the majority of individuals. Moreover, we now appreciate the importance of individualizing dietary fat recommendations within this range of total fat. With respect to cardiovascular disease, a diet higher in total fat (30-35\% energy) affects the lipid and lipoprotein risk profile more favourably than a lower-fat diet; this is also the case for individuals with diabetes, with the added benefit of better glycaemic control. Dietary fibre $(\geq 25 \mathrm{~g} / \mathrm{d})$ attenuates and even prevents the potentially adverse lipid and lipoprotein effects of a lower-fat diet. With respect to weight control, a moderate-fat diet can be as, or even more, effective than a lower-fat diet, because of advantages with long-term adherence and potentially favourable effects on lipids and lipoproteins. Thus, there is now a convincing scientific basis to advocate a diet moderate in total fat for the majority of individuals. Implicit to this position is that unsaturated fat has numerous beneficial health effects. However, because fat is energy dense, moderation in fat intake is essential for weight control. Consequently, a simple message to convey is to avoid diets that are very low and very high in fat. Moreover, within the range of a moderate-fat diet it is still important to individualize the total fat prescription. Nonetheless, the guiding principle is that moderation in total fat is the defining benchmark for a contemporary diet that reduces risk of chronic disease.
\end{abstract}

Moderate-fat diet: Lipoprotein metabolism: Health benefits: Cardiovascular disease: Type 2 diabetes: Weight control

Inherent to the evolution of dietary guidance has been the question of what is the optimal amount of dietary fat that confers the greatest health benefit? For many years the objective was to continue reducing dietary fat, because of the presumed and demonstrated health benefits of a low-fat diet. However, evidence began to emerge demonstrating that diets low in total fat were associated with some potentially adverse effects on chronic disease, as manifested by their effects on important end-point markers. At the same time, a number of studies reported that diets higher in total fat and specifically high in unsaturated fatty acids conferred unexpected health benefits. As is always the case in science when evidence is presented that challenges the existing dogma, spirited debate occurs which can only be resolved by further research. Moreover, subsequent research needs to robustly test alternative hypotheses. We are transiting a time of active research to identify the optimal level of dietary fat as it relates to risk of various chronic diseases. Different experimental approaches are being implemented in human subjects that range from epidemiological to controlled clinical studies to intervention studies that critically evaluate the health benefits and risks of varying the type and amount of fat in the diet.

Historically, it is important to appreciate that total fat consumption varies markedly among populations worldwide. For example, the Bantus of Africa consume a very-low-fat diet providing approximately $10 \%$ energy (\% en) from fat, whereas some native Eskimo populations

\footnotetext{
Abbreviations: CHO, carbohydrate; CVD, cardiovascular disease; $\%$ en, percentage energy; MUFA, monounsaturated fatty acids; PUFA, polyunsaturated fatty acids; RR, relative risk; SFA, saturated fatty acids; TG, triacylglycerols.

*Corresponding author: Dr Penny Kris-Etherton, fax +1 8148636026 , email pmk3@psu.edu
} 
consume more than $60 \%$ en from fat (Smith, 1997). Most Western cultures consume a diet that lies between these extremes, providing approximately $25-40 \%$ en (FAO food balance sheets; Food and Agriculture Organization, 2001), which still represents an appreciable range in fat intake. Moreover, there are considerable differences in the fatty acid profile of these diets, with Western societies consuming diets high in saturated fat (SFA), whereas Native Eskimos consume diets high in $n$ - 3 fatty acids. The diversity in the fatty acid profile is important, because of demonstrated effects on health. Collectively, the population data in conjunction with other experimental data were critical in establishing the concept that type and amount of fat are important considerations for making dietary recommendations.

As our understanding of the role of type and amount of fat in the diet, as it relates to health, has progressed, we have been able to make appropriate and requisite changes in dietary recommendations. Very recently, we have taken major steps in modifying our dietary guidelines. Previous recommendations focused on the population at large, and delivered a low-fat message. More recently, the US dietary guidelines (US Department of Agriculture/US Department of Health and Human Services, 2000) have recommended a diet moderate in total fat. While the new guidelines continue to recommend a diet that provides $\leq 30 \%$ en from total fat, no longer is a low-fat diet being emphasized. The newlyreleased Adult Treatment Panel Report of the National Cholesterol Education Program Expert Panel (2001) recommends a range in fat intake from 25 to $35 \%$ en from fat, with an emphasis on keeping saturated fat at $<7 \%$ en. An important aspect of the new guidance is to avoid a very-low-fat diet, because of possible consequent adverse health effects, as well as difficulties with adherence. The previous and newly-released American Heart Association dietary guidelines (Krauss et al. 2000) support a total fat recommendation of $\leq 30 \%$ en, and recognize the need for individualizing dietary fat recommendations on the basis of an individual's clinical profile. Collectively, the new dietary recommendations acknowledge the health benefits of unsaturated fat. Thus, the present paper will provide an overview of the health effects of dietary fat as it relates to major chronic diseases (e.g. cardiovascular disease (CVD), diabetes and overweight and obesity) in Western societies. It is now abundantly clear that dietary fat recommendations must be individualized. For some individuals a diet lower in total fat is preferable, whereas for other individuals a moderate-fat diet is more appropriate to reduce risk of chronic diseases. Further research is needed to optimize guidance for both lower- and higher-fat diets to maximally reduce risk of chronic diseases.

\section{Cardiovascular disease}

\section{Epidemiological studies}

Based on the epidemiological studies reported to date, there is some evidence that total fat is associated with CHD, whereas other reports have not observed an association. In the studies that do report a significant positive association, however, the strength of the relationship is relatively modest, especially compared with that reported for type of fat and dietary cholesterol. In the Seven Countries Study (Keys, 1970) there was a modest positive association between $\%$ en from total fat and CHD deaths and infarctions $(r 0.40)$. Furthermore, there was a significant relationship between \% en from SFA and CHD deaths and infarctions ( $r$ 0.84) and 10-year incidence of CHD ( $r 0.80$; Keys et al. 1986). In addition, dietary cholesterol was positively associated with incidence of CHD $(r 0.81)$. The Honolulu Heart Program (McGee et al. 1985) reported a weak association $(r 0.247, P<0.05)$ between $\%$ en from total fat and mortality from CHD after adjusting for age, systolic blood pressure, BMI, physical activity index, and number of cigarettes smoked per $\mathrm{d}$, in a population of Japanese men $(n 1088)$ residing in Honolulu. The \% en from SFA was significantly related to CHD mortality after adjusting for CHD risk factors ( $\beta$ coefficient 0.255 , $P<0.05$ ). The Framingham Heart Study (Posner et al. 1991) also showed that after adjusting for CHD risk factors there were positive associations between \% en from total fat and incidence of CHD over 16 years in men aged 45-55 years ( $\beta$ coefficient $0.035, \quad P=0.05$ ). There were positive associations between total energy from SFA and from monounsaturated fat (MUFA) and incidence of CHD ( $\beta$ coefficient $0.047, P=0.052$ and $\beta$ coefficient 0.071 , $P=0.004$ respectively). There were no associations between total fat and incidence of CHD in the older (55-65 years of age) population of men. A recent study by Suh et al. (2001) found a significant association between total fat and IHD in Korean men. After adjusting for IHD risk factors, \% en from total fat was positively associated with IHD (odds ratio 1.08 $(95 \%$ CI $1.02,1.14)$ ). When examining quartiles of total fat intake and risk of IHD there was a trend for an association between total fat and IHD risk; however, this association did not attain significance until total fat intake (as \% total en) was $>25 \%$. Suh et al. (2001) also examined whether the type of fat affects risk of IHD. In multivariate analyses, when total fat was not controlled for (but IHD risk factors were), SFA intake and MUFA intake were both positively associated with IHD risk (odds ratio 1.15 (95\% CI 1.02 , 1.30) for SFA, odds ratio $1.12(95 \%$ CI $1.01,1.25)$ for MUFA). However, after adjusting for total fat intake, these associations were not significant, possibly due to low intakes and narrow ranges of individual fatty acids (6-7\% en from SFA, 6.4-7.5\% en from MUFA, $4 \cdot 1-4.4 \%$ en from polyunsaturated fatty acids (PUFA)).

Several studies have not reported an association between total fat and risk of CHD. The Nurses' Health Study (Hu et al. 1997) examined the relationship between total fat and risk of CHD in women, and found that after adjusting for CHD risk factors there was no association between total fat intake and risk of CHD (relative risk (RR) $1.02(95 \%$ CI $0.97,1.07)$ ). There was a trend, however, for a positive association between SFA intake and CHD risk (RR 1.17 (95\% CI 0.97, 1.41), P=0.10), and there were inverse associations between MUFA intake and PUFA intake and risk of CHD (RR $0.81(95 \%$ CI $0.65,1.00), P=0.05$ for MUFA; RR 0.62 (95\% CI 0.46, 0.85), $P=0.003$ for PUFA). The Zutphen Study (Kromhout \& Coulander, 1984), also, did not find an association between total fat intake and 10 -year mortality from CHD in middle-aged men $(n 871)$. 
The epidemiological studies, in general, show that type of fat is important in establishing CHD risk, and that total fat seems to be of lesser consequence. However, there is evidence that a low-fat diet may actually increase risk of ischaemic stroke. The Framingham Heart Study (Gillman et al. 1997) examined the association between dietary fat and risk of ischaemic stroke during 20 years of follow-up in men. After adjusting for age, for every increasing quintile of total fat, SFA and MUFA there was a decrease in risk of ischaemic stroke $(P=0.008, P=0.002$ and $P=0.008$ respectively). Furthermore, after adjusting for $\mathrm{CHD}$ risk factors, for every $3 \%$ increase in total fat there was a $15 \%$ decrease in risk of ischaemic stroke $(P=0.002)$, and for every $1 \%$ increase in energy from SFA as well as MUFA, risk of ischaemic stroke decreased 9 and $11 \%$ respectively $(P=0.01$ and $P=0.003)$. Similar findings were also observed in the Honolulu Heart Program (McGee et al. 1985), which showed an inverse association between $\%$ en from total fat and from SFA and mortality from stroke $(r-0.302$ and -0.366 respectively, $P<0.05)$. These studies suggest that there may be unintended health consequences (i.e. ischaemic stroke) associated with lowering total fat too much.

\section{Clinical studies}

Some of the early clinical studies (Dayton et al. 1969; Leren, 1970; Turpeinen et al. 1979) demonstrated beneficial effects of a diet higher in total fat ( $\geq 35 \%$ en) from PUFA that were also low in SFA on primary and secondary prevention of IHD (or CHD) (Table 1). Dietary cholesterol, also, was lower in the treatment groups. These studies were the first to demonstrate a marked decrease in serum cholesterol levels $(-13$ to $-16 \%)$ and a concomitant decrease in cardiovascular events in response to diet. In contrast, the Research Committee of the Medical Research Council (1968) trial failed to observe a decrease in coronary events, despite a $16 \%$ decrease in serum cholesterol levels in subjects on a diet high in PUFA. The finding of a decreased incidence of cardiovascular events in the early studies of cholesterol-lowering with diets higher in total fat and PUFA (and lower in SFA and cholesterol) is not surprising given the magnitude of cholesterol reduction (Holme, 1990).

In more recent studies, a diet lower in total fat has been shown to beneficially affect the incidence of recurrent coronary artery disease (Ornish et al. 1998; de Lorgeril et al. 1999). In the Lyon Diet Heart Study (de Lorgeril et al. 1999), the experimental group followed a diet lower in total fat (i.e. $30 \%$ en $v .34 \%$ en) and SFA ( $8 \%$ en $v .12 \%$ en) and higher in $\alpha$-linolenic acid $(0.8 \%$ en $v .0 .3 \%$ en) compared with the usual-care group. Surprisingly, there were no differences in plasma lipids and lipoproteins between the experimental and usual-care groups. Nonetheless, there was a remarkable decrease (about $70 \%$ ) in all coronary events in the experimental group starting after 1 year of follow-up. In a more restrictive diet approach combined with a total lifestyle intervention programme (vegetarian diet that provided $<10 \%$ en from total fat) there was a decrease in percentage diameter stenosis and the number of cardiac events during the 5-year follow-up (Ornish et al. 1998).
Thus, there is evidence that across the spectrum of fat intake ranging from $<10 \%$ en to approximately $40 \%$ en a beneficial effect on incidence of cardiovascular events can be realised by diet provided that SFA and cholesterol are low. It is likely that multiple mechanisms are involved, given that event incidence decreased in studies that reported both a decrease and no change in serum cholesterol levels.

Clinical studies have evaluated the effects of amount of dietary fat (and reciprocally dietary carbohydrate (CHO)) on a number of risk factors for CVD (Kris-Etherton et al. 1999). The evidence is clear that SFA and cholesterol should be decreased in the diet. The ensuing question is what is the preferable replacement for SFA energy in the diet? Alternatively, in the case of a hypoenergetic diet (due to a decrease in SFA) what is the ideal macronutrient profile of the diet? A number of controlled clinical studies have been done to evaluate diets higher in total fat from unsaturated fat, principally MUFA, $v$. lower-fat diets (both low in SFA). Both diets evoke beneficial effects on some risk factors of CVD, which has resulted in the current discussion of whether one diet is preferable or, alternatively, can both be used in a way that is determined by an individual's clinical profile?

These questions were addressed in the Dietary Effects on Lipoproteins and Thrombogenic Activity Study, a multicentre study designed to rigorously evaluate the effects of type and amount of dietary fat on lipids, lipoproteins and thrombogenic activity in different population groups. Two different protocols were conducted and three diets were evaluated in each protocol using a randomized, crossover study design: (1) protocol 1 evaluated the effects of a stepwise reduction in total fat and SFA (replaced isoenergetically with $\mathrm{CHO}$ ) in healthy subjects (total fat decreased from 37 to $30 \%$ en, and further to $26 \%$ en; SFA decreased from 16 to $9 \%$ en, and further to $5 \%$ en); (2) protocol 2 assessed the effects of substituting either MUFA (37\% en from total fat, $22 \%$ en from MUFA, and $47 \%$ en from $\mathrm{CHO}$ ) or dietary $\mathrm{CHO}$ ( $30 \%$ en from total fat, $15 \%$ en from MUFA, and $54 \%$ en from $\mathrm{CHO}$ ) for SFA on lipids, lipoproteins and haemostatic factors in subjects presenting with indicators for metabolic syndrome (low HDL-cholesterol, high triacylglycerols (TG) and/or high plasma insulin levels). As expected in protocol 1 step-wise reductions in SFA (from 16 to 9 to $5 \%$ en) resulted in a corresponding decrease in LDL-cholesterol by 6.9 and $10.7 \%$ respectively (Ginsberg et al. 1998). However, the reduction in SFA was associated with a decrease in HDL-cholesterol ( 7 and $12 \%$ respectively) and an increase in TG levels (8 and $9 \%$ respectively) as well as lipoprotein(a) levels (10 and $17 \%$ respectively), all changes that could potentially increase risk of CVD. The lowering of HDL-cholesterol was the result of a decrease in both large $\left(\mathrm{HDL}_{2}\right.$ and $\left.\mathrm{HDL}_{2 \mathrm{~b}}\right)$ and small dense HDL sub-populations; the most pronounced decrease observed was for $\mathrm{HDL}_{2}$ and $\mathrm{HDL}_{2 \mathrm{~b}}$ (Berglund et al. 1999). In protocol 2 substituting MUFA ( $37 \%$ en from total fat, $22 \%$ en from MUFA and $47 \%$ en from CHO) $v$. CHO (30\% en from total fat, $15 \%$ en from MUFA and $54 \%$ en from $\mathrm{CHO}$ ) for SFA resulted in a similar decrease in LDLcholesterol $(-6.3 \% v .-7.0 \%)$, however, the low-fat highCHO diet decreased HDL-cholesterol by $7.7 \%$ and increased TG by $6.9 \%$ (Kris-Etherton, 1996). In contrast, 


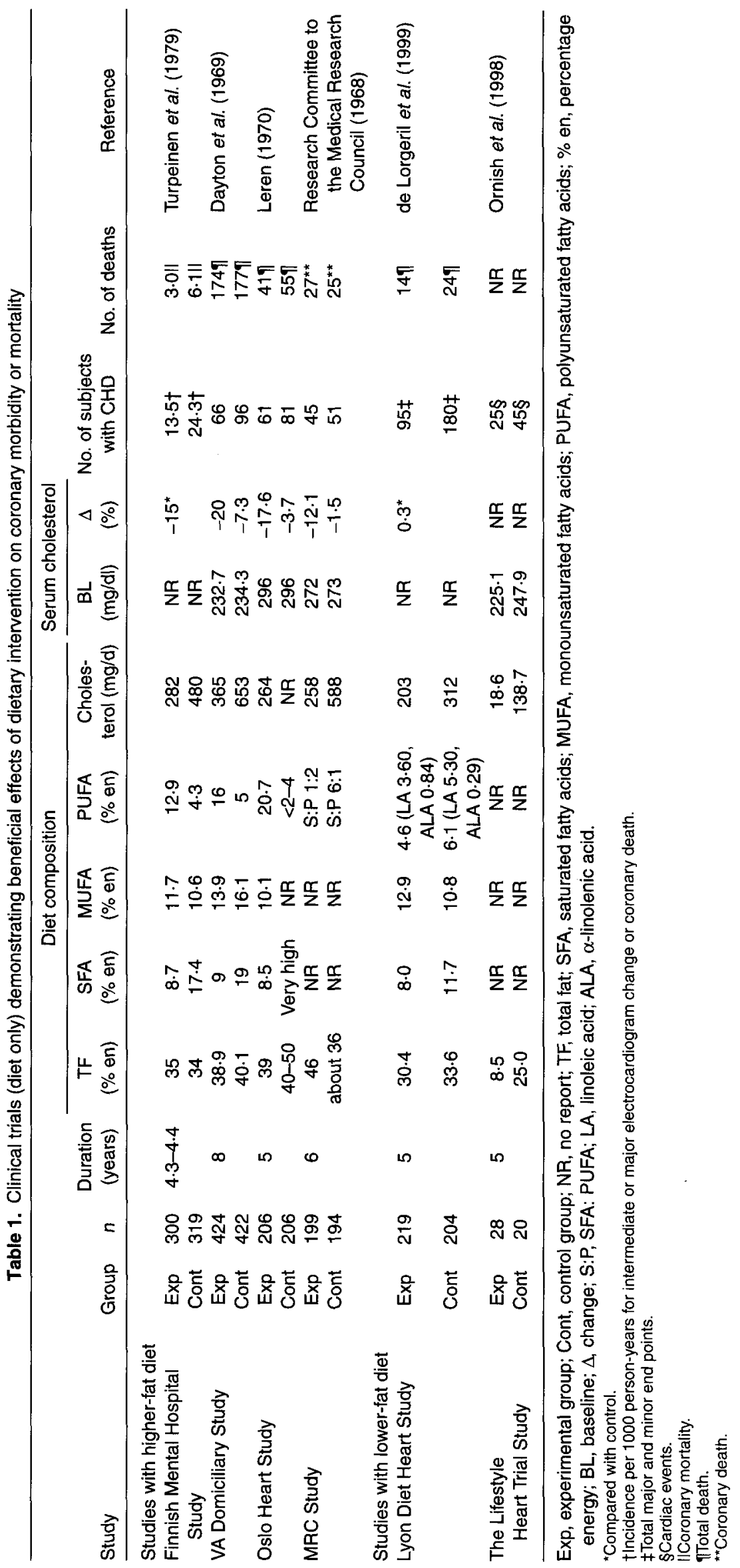


the diet high in MUFA decreased TG by $4.6 \%$ and resulted in only a modest decrease in HDL-cholesterol (by $4.1 \%$; Kris-Etherton, 1996). With respect to haemostatic factors in protocol 1, reductions in SFA (from 16 to 9 to $5 \%$ en) resulted in a modest but significant decrease in Factor $\mathrm{VII}_{\mathrm{c}}$. (1.6 and $2.5 \%$ respectively) and small increases in fibrinogen ( 1.1 and $2.6 \%$ respectively) and plasminogen activator inhibitor-1 ( 1.0 and $9.4 \%$ respectively; $P<0.01$; Elmer et al. 1995). In protocol 2 reducing SFA decreased Factor $\mathrm{VII}_{\mathrm{c}}$ by approximately $3 \%$; however, the diet high in MUFA did not increase fibrinogen, whereas the low-fat diet did (increased by $4.2 \%$; Elmer et al. 1996). Thus, the Dietary Effects on Lipoprotein and Thrombogenic Activity Study demonstrated that a low-fat diet was associated with potentially adverse effects on important risk factors for CVD.

Another possible adverse effect of a low-fat diet has been reported by Krauss \& Dreon (1995). They found that about one-third of individuals who present with large buoyant LDL (pattern A) experienced a shift to a pattern B LDL profile (smaller denser LDL) in response to a low-fat diet. This shift may increase risk of CVD, because the available evidence suggests that smaller denser LDL are more atherogenic. These investigators showed, however, that a low-fat diet may be preferable in individuals with a stable B LDL profile, since they experienced greater reductions in LDL-cholesterol, apolipoprotein B and mass of mid-sized and small LDL subfractions. Other evidence that a low-fat diet may be preferable is based on the study by Asztalos et al. (2000). These investigators found that subjects with low HDL-cholesterol experienced the greatest decreases in LDL-cholesterol with no change in HDL-cholesterol, resulting in an improved LDL:HDL. In subjects with higher HDL-cholesterol, LDL:HDL did not change on a low-fat diet, due to a decrease in both LDL- and HDL-cholesterol. Thus, for some individuals a low-fat diet may be preferable, whereas for others a diet higher in total fat clearly would be preferred (for review, see Krauss, 2001).

\section{The role of dietary fibre}

The hypertriacylglycerolaemic response to a diet low in total fat and high in $\mathrm{CHO}$, but low in fibre, has been documented over the past 50 years (Parks \& Hellerstein, 2000). In fact, efforts to decrease total fat in the diet in recent years are thought to have increased $\mathrm{CHO}$-induced hypertriacylglycerolaemia in many individuals (Anderson, 2000). Recently, elevated levels of blood TG have been considered an independent risk factor for CHD (Cullen, 2000). A meta-analysis concluded that a $1 \mathrm{mmol} / \mathrm{l}$ increase in TG levels is associated with a 76 and $31 \%$ increase in CVD risk in women and men respectively (Austin, 1999). Thus, prevention of hypertriacylglycerolaemia through diet manipulations has become an important concern regarding public health.

Epidemiological evidence confirms the association of a high dietary fibre intake and lower risk of CHD (Rimm et al. 1996). Soluble fibres, such as $\beta$-glucan, pectin and psyllium, have been shown to reduce total cholesterol and LDL-cholesterol beyond what is expected on a cholesterollowering diet (Brown et al. 1999). In addition, evidence is emerging that fibre, particularly the soluble type, may play a therapeutic role in preventing the hypertriacylglycerolaemic response to a high-CHO diet (Anderson, 2000).

Anderson (2000) reviewed fourteen studies to evaluate the extent to which dietary fibre attenuates CHO-induced hypertriacylglycerolaemia. Factors that influence TG levels, such as weight loss may, however, confound results, making interpretation difficult. Anderson (2000) consistently found that high-CHO (60\% en from $\mathrm{CHO}$ ), low-fibre ( $6 \mathrm{~g} / 4.2 \mathrm{MJ}$ $(1000 \mathrm{kcal}))$ diets resulted in higher fasting serum TG levels by a mean of $53(95 \%$ CI 34,71$) \%$, compared with low$\mathrm{CHO}(<45 \%$ en from $\mathrm{CHO}$ ), low-fibre diets. In contrast, high-CHO high-fibre $(29 \mathrm{~g} / 4 \cdot 2 \mathrm{MJ}(1000 \mathrm{kcal}))$ diets lowered TG by 10 (95\% CI $-2,-17) \%$ compared with low-CHO ( $42 \%$ en from $\mathrm{CHO}$ ), low-fibre $(7.5 \mathrm{~g} / 4.2 \mathrm{MJ}$ $(1000 \mathrm{kcal}))$ diets in diabetic subjects.

A recent study in 436 hypercholesterolaemic subjects by Obarzanek et al. (2001) lends further support to the evidence that a high dietary fibre intake prevents CHO-induced hypertriacylglycerolaemia. A control diet (50\% en from $\mathrm{CHO}, 37 \%$ en from total fat, $11 \mathrm{~g}$ fibre/d) was compared with the diet designed for the Dietary Approaches to Stop Hypertension Trial, which was rich in low-fat dairy products, fruit and vegetables $(58 \%$ en from $\mathrm{CHO}, 27 \%$ en from total fat, $30 \mathrm{~g}$ fibre/d). The experimental diet significantly lowered total cholesterol and LDLcholesterol $(P<0.0001)$ without altering plasma TG when compared with the control diet. Furthermore, Chandalia et al. (2000) conducted a crossover study in subjects with type 2 diabetes to assess the effect of a moderate-CHO (55\% en from $\mathrm{CHO}$ ) high-fibre diet on lipid levels. Increasing dietary fibre intake to $22 \mathrm{~g} / 4.2 \mathrm{MJ}(1000 \mathrm{kcal})$ resulted in a $10.2 \%(P<0.02)$ decrease in fasting serum TG levels compared with a diet with only $10 \mathrm{~g}$ fibre $/ 4.2 \mathrm{MJ}$ $(1000 \mathrm{kcal})$. In addition, total cholesterol and LDLcholesterol also decreased by 6.7 and $12.5 \%(P<0.02)$ respectively, while HDL-cholesterol was not altered.

Diets with a moderate fibre content have a variable effect on lipid levels. Anderson (2000) reviewed four outpatient studies which reported that moderate-CHO $(57 \%$ en from $\mathrm{CHO}, 26 \%$ en from total fat) moderate-fibre $(19 \mathrm{~g} / 4 \cdot 2 \mathrm{MJ}(1000 \mathrm{kcal})$ diets reduced blood TG by 28 $(95 \% \mathrm{CI}-17,-38) \%$ compared with diets with $45 \%$ en from CHO, $35 \%$ en from total fat and $8.4 \mathrm{~g}$ fibre $/ 4.2 \mathrm{MJ}$ $(1000 \mathrm{kcal})$. A crossover study in diabetic men found that fasting serum TG levels did not significantly change during a high-CHO (70\% en) high-fibre ( $34 \mathrm{~g} / 4.2 \mathrm{MJ}(1000 \mathrm{kcal}))$ diet; however, a high-CHO (70\% en) moderate-fibre $(12 \mathrm{~g} / 4.2 \mathrm{MJ}(1000 \mathrm{kcal}))$ diet was associated with a $23 \%$ increase in TG $(P<0.01$; Anderson et al. 1980). Garg et al. (1992) conducted a study comparing the TG response of two diets matched for fibre content $(25 \mathrm{~g} / \mathrm{d})$, but varied in levels of $\mathrm{CHO}$ in hypertriacylglycerolaemic subjects with diabetes. The high-CHO diet $(60 \%$ en from $\mathrm{CHO})$ resulted in a $27.5 \%(P<0.002)$ increase in plasma TG compared with the low-CHO diet $(35 \%$ en from $\mathrm{CHO}$ ). Thus, further research is needed to define the optimal value for fibre: $\mathrm{CHO}$ in the diet, as well as to elucidate the mechanism by which dietary fibre averts elevations in TG.

Based on available evidence, inclusion of high-fibre foods may attenuate or prevent adverse metabolic effects 
associated with high-CHO diets. In clinical practice, when implementing a low-fat high-CHO diet recommendations should be made to simultaneously increase fibre-dense foods in concert with dietary $\mathrm{CHO}$.

\section{The role of dietary protein}

Studies evaluating the effects of dietary macronutrients on CVD risk factors have manipulated the fat and $\mathrm{CHO}$ contents of the diet while holding protein content constant $(10-20 \%$ en). Nonetheless, there is a growing body of evidence about the effects of dietary protein, from both animal and plant origin, on CVD risk.

While some epidemiological studies have reported that animal protein intake is associated with greater CVD-related mortality (Slattery et al. 1991; Menotti et al. 1999) a correlation between animal protein intake and SFA and cholesterol intakes has also been observed (Stamler, 1979). More recently, results from the Nurses' Health Study found that high protein intakes (up to $24 \%$ en) significantly reduced the risk of IHD (RR 0.75 (95\% CI 0.61, 0.92; Hu et al. 1999). Perhaps of most interest is that this relationship persisted in women consuming lower-fat ( $33 \%$ total en; RR $0.76(95 \%$ CI $0.55,0.16))$ and higher-fat diets $(42 \%$ total en; RR $0.72(95 \%$ CI $0.52,1.01))$.

Consistent with the epidemiological evidence demonstrating a beneficial effect of the amount of a higher-protein diet on risk of coronary artery disease, a controlled clinical study reported beneficial effects of a higher-protein diet on plasma lipids and lipoproteins (Wolfe \& Giovannetti, 1991). In this study subjects with moderate hypercholesterolaemia were randomly assigned to either a high-protein diet containing $27 \%$ en from protein (79\% animal protein) and $53 \%$ en from $\mathrm{CHO}$ or a low-protein diet $(11 \%$ en from protein, $65 \%$ en from $\mathrm{CHO}$ ). Dietary fat ( $25 \%)$, cholesterol $(<200 \mathrm{mg} / \mathrm{d})$ and fibre were held constant. Compared with subjects on the low-protein diet, subjects on the high-protein diet experienced a $5.7 \%$ reduction in total cholesterol $(P<0.001)$ and LDL-cholesterol $(P<0.01), 23 \%(P<0.02)$ reduction in total TG, and a $12 \%(P<0.01)$ increase in HDL-cholesterol.

There is evidence that protein source is also important. A meta-analysis of thirty-eight controlled clinical trials concluded that soyabean intakes ranging from 31 to $47 \mathrm{~g} / \mathrm{d}$ significantly reduced total cholesterol by $9.3 \%$, LDLcholesterol $(95 \% \mathrm{CI}-329,-135 \mathrm{mg} / \mathrm{l})$ by $12.9 \%(95 \%$ $\mathrm{CI}-317,-11.2 \mathrm{mg} / \mathrm{l})$, and TG by $10.5 \%(95 \% \mathrm{CI}-257$ to $-3 \mathrm{mg} / \mathrm{l}$ ), and HDL-cholesterol was increased modestly (i.e. $2.4 \%$; NS); (Anderson et al. 1995). It is important to note that this meta-analysis, as well as other studies, confirms that the hypocholesterolaemic effect of soyabean protein is dependent on baseline cholesterol levels, with a greater response observed in subjects with higher baseline cholesterol levels. However, the results of this study have been scrutinized recently (Lichtenstein, 2001), and more recent studies continue to report variable cholesterolaemic effects of soyabean protein. For example, Crouse et al. (1999) did not observe any significant changes in total cholesterol, LDL-cholesterol, HDL-cholesterol or TG with $25 \mathrm{~g}$ isolated soyabean protein containing only trace amounts of soyabean isoflavones/d compared with $25 \mathrm{~g}$ casein/d in mildly hypercholesterolaemic men and women. On the other hand, a dose-response effect was reported where $25 \mathrm{~g}$ soyabean protein with $62 \mathrm{mg}$ isoflavones significantly reduced plasma total cholesterol $(4 \%, P=0.04)$ and LDL-cholesterol $(6 \%, P=0.01)$ compared with soyabeanprotein diets containing $3-27 \mathrm{mg}$ isoflavones in mildly hypercholesterolaemic volunteers (Crouse et al. 1999). It has been proposed that the hypocholesterolaemic effect of soyabean protein is due to both soyabean isoflavones and the protein per se.

Other protein sources have been shown to beneficially affect lipid risk factors for CVD. There have been some investigations showing that a lean-fish (i.e. cod, sole) diet compared with a non-fish diet (i.e. beef, veal, pork, eggs and milk) in diets containing $30 \%$ en from fat and high in unsaturated fatty acids reduced plasma VLDL-TG in premenopausal women (Gascon et al. 1996) and VLDL-TG:apolipoprotein B in men (Lacaille et al. 2000), and increased $\mathrm{HDL}_{2}$-cholesterol in men (Lacaille et al. 2000). However, Jacques et al. (1992) found that concentrations of plasma total cholesterol and HDL- and $\mathrm{HDL}_{3-}$ cholesterol remained unchanged in post-menopausal women fed a diet rich in lean fish.

A low-SFA higher-protein diet $(20-30 \%$ en from protein) could be considered an alternative to more traditional low-fat high-CHO diets for CVD risk reduction, particularly in the case of hypertriacylglycerolaemia and for those who are unable or unwilling to adhere to a low-fat high-CHO diet. Caution is warranted, however, in recommending a higher-protein diet. Increasing protein intake from animal sources such as meat and dairy can result in increased intakes of SFA and cholesterol if lean meats and low-fat dairy products are not selected. Thus, plasma cholesterol levels may be adversely affected and override any benefit gained from increasing protein in the diet. Although current research shows a promising role for dietary protein in CVD risk reduction, more research is needed to fully elucidate the role of protein in CVD risk reduction.

\section{Type 2 diabetes}

The relationship between dietary fat and glucose metabolism has been studied in both animals and man. In early animal studies high-fat feeding resulted in hyperglycaemia and impaired glucose tolerance; the latter was associated with decreased basal and insulin-stimulated glucose utilization (Grundleger \& Thenen, 1982; Storlien et al. 1986). With respect to insulin sensitivity, dietary SFA has been shown to be more deleterious compared with MUFA and PUFA. In recent studies (Fickova et al. 1998; Jucker et al. 1999), adding $n-3$ fatty acids to the diets ameliorated some of the effects induced by feeding a high-fat diet. In healthy subjects with normal glucose metabolism no difference between the high-fat $v$. low-fat high-CHO diet has been observed. Coulston et al. (1983) compared a high-fat diet (41\% en from total fat, $40 \%$ en from $\mathrm{CHO}$ ) with a low-fat diet $(21 \%$ en from fat, $60 \%$ en from $\mathrm{CHO}$ ) in healthy volunteers and no difference in 
fasting plasma glucose and insulin concentrations were found. In another study conducted by Borkman et al. (1991) mean whole-body glucose uptake during glucose infusion and fasting blood glucose and insulin concentrations were similar in normal subjects who consumed either high-fat diets $(50 \%$ en from total fat) or low-fat diets $(20 \%$ en from total fat). In contrast, Lichtenstein \& Schwab (2000) concluded that high-fat diets, independent of fatty acid profile, decrease insulin sensitivity. Interestingly, SFA $v$. MUFA and PUFA appear to have a more deleterious effect. Moreover, some of the adverse effects can be attenuated with $n-3$ fatty acids. In addition, metabolic studies suggest that higher-fat diets containing a higher proportion of unsaturated fat more favourably affect measures of glucose metabolism than a high-CHO diet (Lichtenstein \& Schwab, 2000).

In patients with type 2 diabetes most studies have reported high-fat diets (i.e. lower in SFA and higher in MUFA and PUFA) result in greater glycaemic control compared with high-CHO diets. Coulston et al. (1987) reported that low-fat high-CHO diets $(20 \%$ en from total fat, $60 \%$ en from $\mathrm{CHO}$ ) resulted in increased glucose and insulin levels in response to normal meal cycles and higher daylong blood glucose and insulin concentrations (Coulston et al. 1989) compared with the high-fat diet ( $40 \%$ en from total fat, $40 \%$ en from $\mathrm{CHO}$ ). A similar finding has been reported in a recent meta-analysis (Garg, 1998) which compared the effects of high-CHO diets (49-60\% en from CHO, 20-32\% en from total fat) $v$. high-MUFA diets $(35-40 \%$ en from $\mathrm{CHO}, 37-50 \%$ en from total fat) in patients with diabetes mellitus. There was a significant lowering of fasting plasma glucose (by 0.23 $(95 \% \mathrm{CI}-0.39,-0.06) \mathrm{mmol} / \mathrm{l} ; P<0.05)$ with consumption of a high-MUFA diet compared with a high-CHO diet. More studies have also shown that high-MUFA diets (37-50\% en from total fat, $22-33 \%$ en from MUFA) lowered postprandial plasma glucose concentrations (Parillo et al. 1992, 1996; Lerman-Garber et al. 1994), reduced peak blood glucose concentrations (Rasmussen et al. 1993), and decreased daylong concentrations of plasma glucose and insulin, and urinary glucose excretion (Garg et al. 1988, 1994; Campbell et al. 1994) in diabetic subjects when compared with high-CHO diets (49-60\% en from $\mathrm{CHO}, 7-13 \%$ en from MUFA). However, some other studies did not observe different effects of a high-CHO diet $v$. a high-fat diet on glycaemic control and insulin sensitivity. Bonanome et al. (1991) compared a high-MUFA diet ( $40 \%$ en from total fat, $25 \%$ en from MUFA, $45 \%$ en from $\mathrm{CHO}$ ) with a high-CHO diet ( $25 \%$ en from total fat, $10 \%$ en from MUFA, $60 \%$ en from $\mathrm{CHO}$ ) and found no difference in glycosylated haemoglobin or fasting plasma glucose, insulin and C-peptide concentrations between the diets. Studies by Garg et al. (1992) and Abbott et al. (1989) reported similar findings. Despite the inconsistent results for glycaemic control and insulin sensitivity, higher-fat high-MUFA diets consistently result in more favourable lipid and lipoprotein profiles, such as lowering VLDL-cholesterol and TG by 22 and $19 \%$ respectively, and modestly increasing HDLcholesterol concentrations by $4 \%$ (Garg, 1998). The improvement in lipid and lipoprotein profiles will benefit diabetic patients.

Decreasing body weight has been shown to favourably affect many metabolic processes, including decreasing postprandial glucose concentrations, increasing insulin sensitivity and favourably affecting the lipid profile. A multi-centre randomized clinical trial (McCarron et al. 1997) with a complete meal plan developed at the Campbell's Center for Nutrition and Wellness (Campbell Soup Co., Camden, NJ, USA) which consisted of $17 \%$ en from total fat and $62 \%$ en from $\mathrm{CHO}$ demonstrated significant decreases in levels of plasma glucose (by $0.65 \mathrm{mmol} / \mathrm{l}$; $P<0.001$ ), plasma insulin (by $20 \mathrm{pmol} / 1 ; P<0.001$ ), and glycosylated haemoglobin (by $0.4 \% ; P<0.001$ ); all these favourable effects may be associated with significant weight loss (i.e -4.5 and $-4.8 \mathrm{~kg}$ for men and women respectively; $P<0.03$ in both cases). A similar result was reported by a recent study (Tuomilehto et al. 2001) in which subjects were counselled to reduce intake of total fat and SFA, and increase intake of fibre and physical activity. Body-weight loss was $4.2 \mathrm{~kg}$ by the end of year 1 and $3.5 \mathrm{~kg}$ by the end of year 2 . The cumulative incidence of diabetes after a 4-year intervention decreased by $12 \%$ and the risk of diabetes was reduced by $58 \%$ compared with the control group. Another report from the Diabetes Prevention Program (Diabetes Prevention Program Website), a major clinical trial conducted at 27 centres nationwide comparing diet and exercise with metformin treatment in 3234 subjects with impaired glucose tolerance, reported that intensive lifestyle changes with the aim of reducing weight by $7 \%$ (approximately $6.8 \mathrm{~kg}$ ) through a low-fat diet (less than $25 \%$ en as total fat) and exercise ( $30 \mathrm{~min} /$ day walking or other moderate-intensity exercise), reduced the risk of getting type 2 diabetes by $58 \%$, whereas the metformin treatment only reduced the risk of getting type 2 diabetes by $31 \%$ during the average follow-up period of 3 years. In addition, diabetes incidence decreased by $14 \%$ in the diet and exercise group compared with $22 \%$ in the metformin treatment group. Consistent with these results is an epidemiological study (Hu et al. 2001) which reported that the adoption of a healthier lifestyle (such as lower BMI, higher cereal fibre and PUFA intakes and lower trans-fat intake and glycaemic load, participation in moderate-to-vigorous physical activity, no current smoking and moderate alcohol consumption) was associated with a reduction in the incidence of diabetes.

Advances in our understanding of diet and glycaemic control support the current dietary recommendations for subjects with diabetes. It is now evident that the nutrition recommendations for patients with diabetes mellitus should be individualized (American Diabetes Association, 2002). For obese patients with acceptable lipid-lipoprotein concentrations, a lower-fat diet (with $<30 \%$ en from total fat) may be appropriate, because of the improvement in weight loss and consequently favourable effects on glucose metabolism and insulin sensitivity. However, for patients with elevated TG or dyslipidaemia, a moderate-fat diet higher in total fat would be adequate for achieving overall beneficial effects. 


\section{Weight control}

The prevalence of overweight and obesity continues to accelerate globally. This factor is a major public health concern, because type 2 diabetes mellitus, hypertension, CVD, dyslipidaemia and osteoarthritis are associated with excess weight. Both the National Institutes of Health/ National Heart, Lung and Blood Institute/Obesity Education Initiative Expert Panel (1998) evidence report, Clinical Guidelines for the Identification, Evaluation, and Treatment of Overweight and Obesity in Adults, and the American Heart Association dietary guidelines (Krauss et al. 2000) recommend a total fat intake of $\leq 30 \%$ total en in order to promote weight loss. The modest reduction in total fat provides a weight-loss strategy, without markedly altering dietary patterns, to facilitate a reduction in energy intake.

Evidence that this approach can be successful is apparent from the National Weight Control Registry, the largest database of individuals who have been successful in maintaining a substantial weight loss long term. Eligibility for enrolment in this database is a weight loss of $\geq 13.6 \mathrm{~kg}$ $(30 \mathrm{lb})$ that has been maintained for $\geq 1$ year $(\mathrm{Klem}$ et al. 1997). Of the various dietary strategies used to achieve weight loss, $33 \cdot 1 \%$ of the participants limited their daily $\%$ en from fat. Dietary intake of fat, protein and $\mathrm{CHO}$, as assessed by food-frequency questionnaire, was 24,19 and $56 \%$ en respectively. Of interest, those participants who gained weight (defined as $>2.5 \mathrm{~kg}$ ) at the 1-year follow-up reported a significant $(P<0.01)$ increase in \% en from fat (with no overall change in total energy intake), while for those who maintained their weight loss there was no significant change (McGuire et al. 1999).

A question of importance relative to weight loss is what is an appropriate level of fat to promote long-term weight loss? Evidence from the National Weight Control Registry study (Klem et al. 1997) and a recent study by McManus et al. (2001) suggests that a moderate amount of dietary fat is preferable for successful weight loss and maintenance of reduced body weight. The study conducted by McManus et al. (2001) evaluated weight loss in subjects consuming a low-fat diet (20\% en from fat) compared with a moderate-fat Mediterranean-style diet consisting of $35 \%$ en from fat. The experimental diets had a similar energy restriction. At the completion of the 18-month study the participation rate was only $20 \%$ for the low-fat diet group, whereas in the moderate-fat diet group it was $54 \%$ $(P<0.002)$. Since the latter group had a greater adherence to the energy-restricted diet than the low-fat diet group, they experienced greater weight loss at 18 months $(-4.1 \mathrm{~kg})$, whereas the low-fat diet group actually gained weight $(+2.9 \mathrm{~kg})$. Thus, a moderate-fat diet provides an effective approach for weight loss and long-term maintenance of reduced body weight. This study is of importance because subjects were followed for 18 months. In another study, Lefevre $e t$ al. (2001) reported a greater weight loss (3.2 v. $1.1 \mathrm{~kg})$ in subjects instructed to follow a Step 1 diet $(<30 \%$ fat, $<10 \%$ SFA, $300 \mathrm{mg}$ cholesterol/d) compared with those on a diet higher in MUFA ( $37 \%$ fat, $<10 \%$ SFA, $300 \mathrm{mg}$ cholesterol/d) for 6 months. Collectively, the studies by McManus et al. (2001) and Lefevre et al. (2001) are supportive of a moderate-fat diet for long-term adherence and perhaps sustained weight loss. Although a study conducted by Schaefer $e t$ al. (1995) reported a mean weight loss of $3.6 \mathrm{~kg}$ in middle-aged men and women who consumed an ad libitum diet that provided $15 \%$ en from fat, questions remain about long-term adherence to a verylow-fat diet.

In a controlled feeding study conducted in our laboratory (Pelkman et al. 2000) we found that a moderate-fat weightloss diet $(32.8 \%$ en from total fat) that resulted in a 7.2 (SD 0.29) $\mathrm{kg}$ weight loss over a 6-week period elicited a more favourable TG and HDL-cholesterol response than did a low-fat diet (18.4\% en from total fat). TG levels decreased by $23 \%$ in the low-fat diet group and $28 \%$ in the moderatefat group in response to weight loss. In response to maintenance of weight loss (4 weeks), we noted a rebound in TG in the low-fat diet group, resulting in even higher levels than baseline. However, in the moderate-fat diet group the decrease in TG levels was maintained. HDL-cholesterol decreased in the low-fat diet group during weight loss and this level was maintained during the weight-maintenance phase. In contrast, HDL-cholesterol levels remained stable during weight loss and maintenance of weight loss in the moderate-fat diet group. Thus, our study shows similar effects of a low-fat diet in response to weight loss and weight maintenance compared with studies in which body weight was maintained. Hence, the benefits of weight loss on TG and HDL-cholesterol are not fully realized with a low-fat diet, at least under controlled feeding conditions during a 4-week weight-maintenance period. Lichtenstein et al. (1994) also reported an increase in TG (22\%) and a decrease in HDL-cholesterol $(-18 \%)$ in subjects who lost $2 \mathrm{~kg}$ over a 10 -week period following a very-low-fat diet consumed ad libitum. Thus, based on the studies by Pelkman et al. (2000) and McManus et al. (2001) a moderate-fat weight-loss diet confers advantages for weight loss with respect to adherence and the plasma lipid and lipoprotein profile compared with a low-fat diet. However, longer-term studies are needed (Lichtenstein \& Van Horn, 1998).

\section{Health benefits of unsaturated fatty acids on cardiovascular disease risk}

The emerging benefits of unsaturated fatty acids on novel CVD risk factors have become an area of active research. These new markers of risk include endothelial function, adhesion molecules, inflammation and postprandial TG clearance. Overall, it is clear that there are multiple benefits of unsaturated fatty acids exhibited by these markers. Improvements in endothelial function have been observed both long term and postprandially with $n-3$ fatty acids (Goodfellow et al. 2000; Mori et al. 2000). The effect of MUFA on these new markers, however, has been shown to be both beneficial when compared with diets higher in SFA and $n-6$ fatty acids (Cuevas et al. 2000; Ryan et al. 2000) and detrimental when compared with low-fat high-CHO meals and $n$-3 fatty acids (Vogel et al. 2000).

Markers of inflammation that are affected by unsaturated fatty acids include interleukin 1, interleukin 6, tumour necrosis factor, C-reactive protein and cell adhesion 
molecules. Supplementation with $n-3$ fatty acids has been shown to suppress the production of cytokines by mononuclear cells (Endres et al. 1989). Furthermore, a reduction in the expression of adhesion molecules will result, due to the reduced production of cytokines. The inhibitory effect on the expression of adhesion molecules by unsaturated fatty acids appears to require at least one double bond, and progressively increases with increasing numbers of double bonds (DeCaterina et al. 2000).

Limited evidence is available concerning the effect of MUFA on postprandial TG-rich lipoproteins, and remains controversial. TG-rich lipoproteins have been shown to be lowered with MUFA when compared with SFA in healthy subjects in a study by Thomsen et al. (1999), while a study by Higashi et al. (1997) reported an increase in both postprandial chylomicrons and their remnants with olive oil when compared with milk fat or safflower oil. However, the reduction in TG-rich lipoproteins by longterm $n-3$ fatty acid supplementation when compared with a high-SFA test meal has been observed in several studies (Williams et al. 1992; Agren et al. 1996). Additionally, n-6 PUFA appear to have an intermediate lowering effect when compared with SFA and $n$ - 3 fatty acids (Zampelas et al. 1994). It will be important to ensure that the diet has adequate amounts of unsaturated fatty acids, in order to reap their many benefits. Further research is necessary in order to discern the optimal amount of these fatty acids.

\section{Summary}

The benefits of a benchmark for total fat anchored in moderation have been shown to decrease risk of chronic disease. Within the range of total fat defined as moderate (i.e. $25-35 \%$ en), some individuals will require a lower fat intake whereas others should consume a higher-fat diet. Extremes in dietary fat should be avoided, but, more importantly, the many health virtues of unsaturated fat are a compelling reason to ensure that fat intake is sufficient to achieve and maintain health.

\section{References}

Abbott WG, Boyce VL, Grundy SM \& Howard BV (1989) Effects of replacing saturated fat with complex carbohydrate in diets of subjects with NIDDM. Diabetes Care 12, 102-107.

Agren JJ, Hanninen O, Julkunen A, Fogelholm L, Vidgren H, Schwab U, Pynnonen O \& Uusitupa M (1996) Fish diet, fish oil, and docosahexaenoic acid rich oil lower fasting and postprandial plasma lipid levels. European Journal of Clinical Nutrition $\mathbf{5 0}$, 765-771

American Diabetes Association (2002) Evidence-based nutrition principles and recommendations for the treatment and prevention of diabetes and related complications. Diabetes Care 25, Suppl., S50-S60.

Anderson JW (2000) Dietary fiber prevents carbohydrateinduced hypertriglyceridemia. Current Atherosclerosis Reports 2, 536-541.

Anderson JW, Chen WJ \& Sieling B (1980) Hypolipidemic effects of high-carbohydrate, high-fiber diets. Metabolism 29 $551-558$
Anderson JW, Johnstone BM \& Cook-Newell ME (1995) Meta-analysis of the effects of soy protein intake on serum lipids. New England Journal of Medicine 333, 276-282.

Asztalos B, Lefevre M, Wong L, Foster TA, Tulley R, Windhauser M, Zhang W \& Roheim PS (2000) Differential response to low-fat diet between low and normal HDL-cholesterol subjects. Journal of Lipid Research 41, 321-328.

Austin MA (1999) Epidemiology of hypertriglyceridemia and cardiovascular disease. American Journal of Cardiology 83, $13 \mathrm{~F}-16 \mathrm{~F}$.

Berglund L, Oliver EH, Fontanez N, Holleran S, Matthews K, Reheim PS, Ginsberg HN, Ramakrishnan R \& Levfevre M (1999) HDL-subpopulation patterns in response to reductions in dietary total and saturated fat intakes in healthy subjects. American Journal of Clinical Nutrition 70, 992-1000.

Bonanome A, Visona A, Lusiani L, Beltramello G, Confortin L, Biffanti S, Sorgato F, Costa F \& Pagnan A (1991) Carbohydrate and lipid metabolism in patients with non-insulin-dependent diabetes mellitus: effects of a low-fat, high-carbohydrate diet vs a diet high in monounsaturated fatty acids. American Journal of Clinical Nutrition 54, 586-590.

Borkman M, Campbell LV, Chisholm DJ \& Storlien LH (1991) Comparison of the effects on insulin sensitivity of high carbohydrate and high fat diets in normal subjects. Journal of Clinical Endocrinology and Metabolism 72, 432-437.

Brown L, Rosner B, Willett WW \& Sacks FM (1999) Cholesterollowering effects of dietary fiber; a meta-analysis. American Journal of Clinical Nutrition 69, 30-42.

Campbell LV, Marmot PE, Dyer JA, Borkman M \& Storlien LH (1994) The high-monounsaturated fat diet as a practical alternative for NIDDM. Diabetes Care 17, 177-182.

Chandalia M, Garg A, Lutjohann D, von Bergmann K, Grundy SM \& Brinkley J (2000) Beneficial effects of high dietary fiber intake in patients with type 2 diabetes mellitus. New England Journal of Medicine 342, 1392-1398.

Coulston AM, Hollenbeck CB, Swislocki AL, Chen YD \& Reaven GM (1987) Deleterious metabolic effects of highcarbohydrate, sucrose-containing diets in patients with noninsulin-dependent diabetes mellitus. American Journal of Medicine 82, 213-220.

Coulston AM, Hollenbeck CB, Swislocki AL \& Reaven GM (1989) Persistence of hypertriglyceridemic effect of low-fat highcarbohydrate diets in NIDDM patients. Diabetes Care 12, 94-101.

Coulston AM, Liu GC \& Reaven GM (1983) Plasma glucose, insulin and lipid responses to high-carbohydrate low-fat diets in normal humans. Metabolism 32, 52-56.

Crouse JR, Morgan T, Terry JG, Ellis J, Vitolins M \& Burke GL (1999) A randomized trial comparing the effect of casein with that of soy protein containing varying amounts of isoflavones on plasma concentrations of lipids and lipoproteins. Archives of Internal Medicine 159, 2070-2076.

Cuevas AM, Guasch V, Castillo O, Irribarra V, Mizon C, San Martin A, Strobel P, Perez D, Germain AM \& Leighton F (2000) A high-fat diet induces and red wine counteracts endothelial dysfunction in human volunteers. Lipids 35, 143-148.

Cullen P (2000) Evidence that triglycerides are an independent coronary heart disease risk factor. American Journal of Cardiology 86, 943-949.

Dayton S, Pearce ML, Hashimoto S, Dixon WJ \& Tomiyasu U (1969) A controlled clinical trial of a diet high in unsaturated fat preventing complications in atherosclerosis. Circulation 39-40, Suppl. II, 63-98.

DeCaterina R, Liao JK \& Libby P (2000) Fatty acid modulation of endothelial activation. American Journal of Clinical Nutrition 71, 213S-223S. 
de Lorgeril M, Salen P, Martin JL, Monjaud I, Delaye J \& Mamelle $N$ (1999) Mediterranean diet, traditional risk factors, and the rate of cardiovascular complications after myocardial infarction: final report of the Lyon Diet Heart Study. Circulation 99, 779-785.

Diabetes Prevention Program Website: http://www.niddk.nih.gov/ welcome/releases/8_8_01.htm/2

Elmer P (1996) Effects of a Step 1 diet and a high monounsaturated (MUFA) fat diet on Hemostatic Factors in Individuals with Markers for Insulin Resistance. FASEB Journal 10, A262.

Elmer PJ (1995) Dietary effects on lipoproteins and thrombogenic activity: Effects of reducing dietary total and saturated fats on hemostatic factors. FASEB Journal 9, A289.

Endres S, Ghorbani R, Kelley VE, Georgilis K, Lonnemann G, van der Meer JW et al. (1989) The effect of dietary supplementation with $n-3$ polyunsaturated fatty acids on the synthesis of interleukin-1 and tumor necrosis factor by mononuclear cells. New England Journal of Medicine 320, 265-271.

Food and Agriculture Organization (2001) FAO food balance sheets. http://apps.fao.org/lim500/nph-wrap.pl?FoodBalance Sheet\&Domain=FoodBalanceSheet.

Fickova M, Hubert P, Cremel G \& Leray C (1998) Dietary ( $n-3)$ and $(n-6)$ polyunsaturated fatty acids rapidly modify fatty acid composition and insulin effects in rat adipocytes. Journal of Nutrition 128, 512-519.

Garg A (1998) High-monounsaturated-fat diets for patients with diabetes mellitus: a meta-analysis. American Journal of Clinical Nutrition 67, Suppl., 577S-582S.

Garg A, Bantle JP, Henry RR, Coulston AM, Griver KA, Raatz SK, Brinkley L, Chen YD, Grundy SM, Huet BA \& Reaven GM (1994) Effects of varying carbohydrate content of diet in patients with non-insulin-dependent diabetes mellitus. Journal of the American Medical Association 271, 1421-1428.

Garg A, Bonanome A, Grundy SM, Zhang ZJ \& Unger RH (1988) Comparison of a high-carbohydrate diet with a high-monounsaturated fat diet in patients with non-insulin-dependent diabetes mellitus. New England Journal of Medicine 319, 829-834.

Garg A, Grundy SM \& Unger RH (1992) Comparison of effects of high and low carbohydrate diets on plasma lipoproteins and insulin sensitivity in patients with mild NIDDM. Diabetes $\mathbf{4 1}$, $1278-1285$.

Gascon A, Jacques H, Moorjani S, Deshaies Y, Brun L-D \& Julien $P$ (1996) Plasma lipoprotein profile and lipolytic activities in response to the substitution of lean white fish for other animal protein sources in premenopausal women. American Journal of Clinical Nutrition 63, 315-321.

Gillman MW, Cupples LA, Millen BE, Ellison RC \& Wolf PA (1997) Inverse association of dietary fat with development of ischemic stroke in men. Journal of the American Medical Association 278, 2145-2150.

Ginsberg HN, Kris-Etherton P, Dennis B, Elmer PJ, Ershow A, Lefevre M, Pearson T, Roheim P, Ramakrishnan R, Reed R, Stewart K, Stewart P, Phillips K \& Anderson N (1998) Effects of reducing dietary saturated fatty acids on plasma lipids and lipoproteins in healthy subjects. Arteriosclerosis Thrombosis and Vascular Biology 18, 441-449.

Goodfellow J, Bellamy MF, Ramsey MW, Jones CJ \& Lewis MJ (2000) Dietary supplements with marine omega-3 fatty acids improve systemic large artery endothelial dysfunction in subjects with hypercholesterolemia. Journal of the American College of Cardiology 35, 265-270.

Grundleger ML \& Thenen SW (1982) Decreased insulin binding, glucose transport, and glucose metabolism in soleus muscle of rats fed a high fat diet. Diabetes 31, 232-237.

Grundleger ML \& Thenen SW (1982) Decreased insulin binding, glucose transport, and glucose metabolism in soleus muscle of rats fed a high fat diet. Diabetes 31, 232-237.
Higashi K, Ishikawa T, Shige H, Tomiyasu K, Yoshida H, Ito T, Nakajima K, Yonemura A, Sawada S \& Nakamura H (1997) Olive oil increased the magnitude of postprandial chylomicron remnants compared to milk fat and safflower oil. Journal of the American College of Nutrition 16, 429-434.

Holme I (1990) An analysis of randomized trials evaluating the effect of cholesterol reduction on total mortality and coronary heart disease incidence. Circulation 82, 1916-1924.

Hu FB, Manson JE, Stampfer MJ, Colditz G, Liu S, Solomon CG \& Willett WC (2001) Diet, lifestyle, and the risk of type 2 diabetes mellitus in women. New England Journal of Medicine 345, 790-797.

Hu FB, Stampfer MJ, Manson JAE, Rimm E, Colditz GA, Rosner BA, Hennekens CH \& Willett WC (1997) Dietary fat intake and the risk of coronary heart disease in women. New England Journal of Medicine 337, 1491-1499.

Hu FB, Stampfer MJ, Manson JE, Rimm E, Colditz GA, Speizer FE, Hennekens CH \& Willett WC (1999) Dietary protein and risk of ischemic heart disease in women. American Journal of Clinical Nutrition 70, 221-227.

Jacques H, Noreau L \& Moorjani S (1992) Effects of plasma lipoproteins and endogenous sex hormones of substituting lean white fish for other animal-protein sources in diets of postmenopausal women. American Journal of Clinical Nutrition 55, 896-901.

Jucker BM, Cline GW, Barucci N \& Shulman GI (1999) Differential effects of safflower oil versus fish oil feeding on insulin-stimulated glycogen synthesis, glycolysis, and pyruvate dehydrogenase flux in skeletal muscle: a $13 \mathrm{C}$ nuclear magnetic resonance study. Diabetes $\mathbf{4 8}, 134-140$.

Keys A (1970) Coronary heart disease in seven countries. American Heart Association Monograph no. 29. New York: American Heart Association.

Keys A, Menotti A, Karvonen MJ, Aravanis C, Blackburn H, Buzina R, Djordjevic BS, Dontas AS, Fibanza F, Keys MH, Kromhout D, Nedeljkovic S, Punsar S, Seccareccia F \& Toshima H (1986) The diet and 15-year death rate in the Seven Countries Study. American Journal of Epidemiology 124, 903-915.

Klem ML, Wing RR, McGuire MT, Seagle HM \& Hill JO (1997) A descriptive study of individuals successful at long-term maintenance of substantial weight loss. American Journal of Clinical Nutrition 66, 239-246.

Krauss RM (2001) Dietary and genetic effects on low-density lipoprotein heterogeneity. Annual Reviews in Nutrition 21, 283-295.

Krauss RM \& Dreon DM (1995) Low-density-lipoprotein subclasses and response to a low-fat diet in healthy men. American Journal of Clinical Nutrition 62, 478S-487S.

Krauss RM, Eckel RH, Howard B, Appel LJ, Daniels SR, Deckelbaum RJ, Erdman JW Jr, Kris-Etherton P, Goldberg IJ, Kotchen TA, Lichtenstein AH, Mitch WE, Mullis R, Robinson K, Wylie-Rosett J, St Jeor S, Suttie J, Tribble DL \& Bazzarre TL (2000) AHA Dietary Guidelines: revision 2000: A statement for healthcare professionals from the Nutrition Committee of the American Heart Association. Circulation 102, 2284-2299.

Kris-Etherton PM (1996) Effects of replacing saturated fat (SFA) with monounsaturated fat (MUFA) or carbohydrates ( $\mathrm{CHO}$ ) on plasma lipids and lipoproteins in individuals with markers for insulin resistance. FASEB Journal 10, A262.

Kris-Etherton PM, Zhao G, Pelkman CL, Fishell VK \& Coval SM (1999) Beneficial effects of a diet high in monounsaturated fatty acids on risk factors for cardiovascular disease. Nutrition in Clinical Care 3, 153-162.

Kromhout D \& Coulander CDL (1984) Diet, prevalence and 10-year mortality from coronary heart disease in 871 middleaged men. American Journal of Epidemiology 119, 733-741.

Lacaille B, Julien P, Deshaies Y, Lavigne C, Brun LD \& Jacques H (2000) Responses of plasma lipoproteins and sex hormones to the consumption of lean fish incorporated in a prudent-type diet 
in normolipidemic men. Journal of the American College of Nutrition 19, 745-753.

Leren P (1970) The Oslo diet-Heart Study; eleven year report. Circulation 42, 936-942.

Lefevre M, Champagne C, Harsha D, Tulley R \& Rood J (2001) Comparison of step 1 versus high-monounsaturated fat diet therapies for CVD risk reductions in free-living subjects with elevated cholesterol. Circulation 104, Suppl. II, 372.

Lerman-Garber I, Ichazo-Cerro S, Zamora-Gonzalez J, CardosoSaldana G \& Posadas-Romero C (1994) Effect of a highmonounsaturated fat diet enriched with avocado in NIDDM patients. Diabetes Care 17, 311-315.

Lichtenstein AH (2001) Got soy? American Journal of Clinical Nutrition 73, 667-668.

Lichtenstein AH, Ausman LM, Carrasco W, Jenner JL, Ordovas JM \& Schaefer EJ (1994) Short-term consumption of a low-fat diet beneficially affects plasma lipid concentrations only when accompanied by weight loss. Arteriosclerosis and Thrombosis 14, 1751-1760.

Lictenstein AH \& Schwab US (2000) Relationship of dietary fat to glucose metabolism. Atherosclerosis 150, 227-243.

McCarron DA, Oparil S, Chait A, Haynes RB, Kris-Etherton P, Stern JS, Resnick LM, Clark S, Morris CD, Hatton DC, Metz JA, McMahon M, Holcomb S, Snyder GW \& Pi-Sunyer FX (1997) Nutritional management of cardiovascular risk factors. A randomized clinical trial. Archives of Internal Medicine 157, 169-177.

McGee D, Reed D, Stemmerman G, Rhoads G, Yano K \& Feinleib $M$ (1985) The relationship of dietary fat and cholesterol to mortality in 10 years: the Honolulu Heart Program. International Journal of Epidemiology 14, 97-105.

McManus K, Antinoro L \& Sacks F (2001) A randomized controlled trial of a moderate-fat, low-energy diet compared with a low-fat, low-energy diet for weight loss in overweight adults. International Journal of Obesity and Related Metabolic Disorders 25, 1503-1511.

McGuire MT, Wing RR, Klem ML, Lang W \& Hill JO (1999) What predicts weight regain in a group of successful weight losers? Journal of Consulting and Clinical Psychology 67, 177-185.

Menotti A, Kromhout D, Blackhorn H, Fidanza F, Buzina R \& Nissinen A (1999) Food intake patterns and 25-year mortality from coronary heart disease: cross-cultural correlations in the Seven Countries Study. The Seven Countries Study Research Group. European Journal of Epidemiology 15, 507-515.

Mori TA, Watts GF, Burke V, Hilme E, Puddey IB \& Beilin LJ (2000) Differential effects of eicosapentaenoic acid and docosahexaenoic acid on vascular reactivity of the forearm microcirculation in hyperlipidemic, overweight men. Circulation 102, 1264-1269.

National Cholesterol Education Program Expert Panel (2001) Executive summary of The Third Report of The National Cholesterol Education Program (NCEP) Expert Panel on detection evaluation, and treatment of high blood cholesterol in adults (Adult Treatment Panel III). Journal of the American Medical Association 285, 2486-2497.

National Institutes of Health/National Heart, Lung, and Blood Institute/Obesity Education Initiative Expert Panel (1998) Clinical Guidelines on the Identification, Evaluation, and Treatment of Overweight and Obesity in Adults. The Evidence Report. Bethesda, MD: NIH.

Obarzanek E, Sacks FM, Vollmer WM, Bray GA, Miller ER, Lin PH, Karanja NM, Most-Windhauser MM, Moore TJ, Swain JF, Bales CW \& Proschan MA for the DASH Research Group (2001) Effects on blood lipids of a blood pressure-lowering diet: the Dietary Approaches to Stop Hypertension (DASH) Trial. American Journal of Clinical Nutrition 74, 80-89.
Ornish D, Scherwitz LW, Billings JH, Brown SE, Gould KL, Merritt TA, Sparler S, Armstrong WT, Ports TA, Kirkeeide RL, Hogeboom C \& Brand RJ (1998) Intensive lifestyle changes for reversal of coronary heart disease. Journal of the American Medical Association 280, 2001-2007.

Parillo M, Rivellese AA, Ciardullo AV, Capaldo B, Giacco A, Genovese S \& Riccardi G (1992) A high-monounsaturatedfat/low-carbohydrate diet improves peripheral insulin sensitivity in non-insulin-dependent diabetic patients. Metabolism 41, 1373-1378.

Parillo M, Giacco R, Ciardullo AV, Rivellese AA \& Riccardi G (1996) Does a high-carbohydrate diet have different effects in NIDDM patients treated with diet alone or hypoglycemic drugs? Diabetes Care 19, 498-500.

Parks E \& Hellerstein M (2000) Carbohydrate-induced hypertriacylglycerolemia: historical perspective and review of biological mechanisms. American Journal of Clinical Nutrition 71, 412-433

Pelkman C, Pearson TA, Maddox D, Fishell V, Juturu V \& Kris-Etherton PM (2000) Effects of peanut-rich (high-MUFA) diet vs. a low-fat diet on plasma lipids and lipoproteins during weight loss and weight maintenance. FASEB Journal 14, 293.

Posner BM, Cobb JL, Belanger AJ, Cupples LA, D‘Agostino RB \& Stokes J III (1991) Dietary lipid predictors of coronary heart disease in men. The Framingham Study. Archives of Internal Medicine 151, 1181-1187.

Rasmussen OW, Thomsen C, Hansen KW, Vesterlund M, Winther E \& Hermansen K (1993) Effects on blood pressure, glucose, and lipid levels of a high-monounsaturated fat diet compared with a high-carbohydrate diet in NIDDM subjects. Diabetes Care 16, 1565-1571.

Research Committee to the Medical Research Council (1968) Controlled trial of soya-bean oil in myocardial infarction. Lancet ii, 693-700.

Rimm EB, Ascherio A, Giovannucci E, Spiegelman D, Stampfer MJ \& Willett WC (1996) Vegetable, fruit, and cereal fiber intake and coronary heart disease among men. Journal of the American Medical Association 275, 447-451.

Ryan M, McInerney D, Owens D, Collins P, Johnson A \& Tomkin GH (2000) Diabetes and the Mediterranean diet: a beneficial effect of oleic acid on insulin sensitivity, adipocyte glucose transport and endothelium-dependent vasoreactivity. Quarterly Journal of Medicine 93, 85-91.

Schaefer EJ, Lichtenstein AH, Lamon-Fava S, McNamara JR, Schaefer MM, Rasmussen H \& Ordovas JM (1995) Body weight and low-density lipoprotein cholesterol changes after consumption of a low-fat ad libitum diet. Journal of the American Medical Association 274, 1450-1455.

Slattery ML, Jacobs DR, Hilner JE, Caan BJ, Van Horn L, Bragg C, Manolio TA, Kushi LH \& Liu KA (1991) Meat consumption and its associations with other diet and health factors in young adults: the CARDIA study. American Journal of Clinical Nutrition 54, 930-935.

Smith MD (1997) Fat facts \& fiction. http://www.healthwell.com

Stamler J (1979) Population studies. In Nutrition, Lipids, and Coronary Heart Disease, pp. 25-88 [RI Levy, BM Rifkind, SC Dennis and N Ernst, editors]. New York: Raven Press.

Storlien LH, James DE, Burleigh KM, Chisholm DJ \& Kraegen EW (1986) Fat feeding causes widespread in vivo insulin resistance, decreased energy expenditure, and obesity in rats. American Journal of Physiology 251, E576-E583.

Suh I, Oh KW, Lee KH, Psaty BM, Nam CM, Kim SI, Kang HG, Cho SY \& Shim WH (2001) Moderate dietary fat consumption as a risk factor for ischemic heart disease in a population with a low fat intake: a case-control study in Korean men. American Journal of Clinical Nutrition 73, 722-727. 
Thomsen C, Rasmussen O, Lousen T, Holst JJ, Fenselau S, Schrezenmeir J \& Hermansen K (1999) Differential effects of saturated and monounsaturated fatty acids on postprandial lipemia and incretin responses in healthy subjects. American Journal of Clinical Nutrition 69, 1135-1143.

Turpeinen O, Karvonen MJ, Pekkarinen M, Miettinen M, Elosuo R \& Paavilainen E (1979) Dietary prevention of coronary heart disease: the Finnish Mental Hospital Study. International Journal of Epidemiology 8, 99-118.

Tuomilehto J, Lindstrom J, Eriksson JG, Valle TT, Hamalainen H, Ilanne-Parikka P, Keinanen-Kiukaanniemi S, Laakso $M$, Louheranta A, Rastas M, Salminen V \& Uusitupa M for the Finnish Diabetes Prevention Study Group (2001) Prevention of type 2 diabetes mellitus by changes in lifestyle among subjects with impaired glucose tolerance. New England Journal of Medicine 344, 1343-1350.

US Department of Agriculture/US Department of Health and Human Services (2000) Nutrition and Your Health: Dietary
Guidelines for Americans, 5th ed. http://www.health.gov/dietary guidelines/dga2000/document/frontcover.htm

Williams CM, Moore F, Morgan L \& Wright J (1992) Effects of $n-3$ fatty acids on postprandial triacylglycerol and hormone concentrations in normal subjects. British Journal of Nutrition 68, 655-666.

Wolfe BM \& Giovannetti PM (1991) Short-term effects of substituting protein for carbohydrate in the diets of moderately hypercholesterolemic human subjects. Metabolism 40, 338-343.

Vogel RA, Corretti MC \& Plotnick GD (2000) The postprandial effect of components of the Mediterranean diet on endothelial function. Journal of the American College of Cardiology 36 , 1455-1460.

Zampelas A, Peel AS, Gould BJ, Wright J \& Williams CM (1994) Polyunsaturated fatty acids of the $n-6$ and $n-3$ series: effects on postprandial lipid and apolipoprotein levels in healthy men. European Journal of Clinical Nutrition 48, 842-848. 